\title{
ACCELERATED LEARNING PROGRAMS FOR OUT- OF-SCHOOL GIRLS: THE IMPACT ON STUDENT ACHIEVEMENT AND TRADITIONAL SCHOOL ENROLLMENT
}

\section{Jennifer Randall ${ }^{1}$}

University of Massachusetts-Amherst, USA

\section{Francis O'Donnell}

University of Massachusetts-Amherst, USA

\section{Sandra M. Botha}

University of Massachusetts-Amherst, USA

\begin{abstract}
Within the context of post-conflict DRC, we examined the impact of the Accelerated Learning Program for out-of-school girls' on student learning outcomes and traditional school enrollment. We found that the vast majority of girls advanced through the levels as expected $(80 \%)$ and, on average, improved their numeracy and literacy skills. The impact on traditional school enrollment was less definitive with the percent of girls who previously attended school, as well as the age of, remaining stable over time, but there was also an increasing trend in the percent of girls who were enrolled in school until the end of the last school year.
\end{abstract}

Keywords: accelerated education programs; accelerated learning programs; post-conflict education; literacy; numeracy

\section{Introduction}

The goal of quality basic education being made accessible for all was established in 1990 during the World Conference on Education for All in Jomtien, Thailand (WCEFA, 1990), and was reiterated in 2004 at the World Education Forum in Dakar, Senegal. In

\footnotetext{
${ }^{1}$ Correspondence: University of Massachusetts, Furcolo Hall, Amherst, MA 01003, USA; Email: jrandall@umass.edu
} 
addition, the fourth sustainable development goal (SDG) proposed by the United Nations relates to quality education with the stated objective of "[ensuring] inclusive and equitable quality education and [promoting] lifelong learning opportunities for all” (United Nations, 2017). Despite these and other efforts, world educational statistics are still concerning.

According to a 2017 report from the UNESCO Institute for Statistics (UIS), roughly "617 million children and adolescents worldwide are not achieving minimum proficiency levels in reading and mathematics" (UIS, September 2017, p. 1). The latest data on out-ofschool children and youth, reported by UIS in February 2018, indicate that "no progress [has been made] in reducing out-of-school numbers" worldwide (UIS, February 2018, p. 1). Approximately 263 million children and youth were out of school in 2016. Roughly 23\% of this population was between 6 and 11 years old (primary school age), 24\% was 12 to 14 years old (lower secondary school age), and 53\% was 15 to 17 years old (upper secondary school age). Sub-Saharan Africa is the region reported to have the highest out-of-school rates for all age groups, with more than half of out-of-school primary school age children living in this region. Southern Asia has the second highest rate, with a reported 10 million out-of-school across all age groups. Additionally, statistics on these out-of-school populations indicate that gender disparities, while improved in some regions, are still a major concern in others.

In the February 2018 report, UIS indicated an overall positive trend in gender disparities; however, the institute expressed concern for numbers at regional and national levels:

In 2000, $54 \%$ of the 378 million out-of-school children, adolescents and youth were female. By 2016, the female share of the global out-of-school population had fallen to $50 \%$. However, these global averages mask considerable differences at regional and national levels (p. 9).

A breakdown of the data at a regional level shows that for primary school age, the widest gender differences were observed in Central Asia. Northern Africa and Western Asia showed the widest gender difference for the lower secondary school age group. In sub-Saharan Africa, girls of any of the age groups were more likely to be excluded from education than their male counterparts. No region has achieved gender equality for any of the age groups (UIS, February 2018). In an effort to address the underlying problems revealed by these statistics, many agencies, governments, and various other stakeholders have worked on implementing programs to overcome these educational issues. In some cases, these programs are implemented as short-term solutions in response to specific needs, while other programs are intended to be long-term educational alternatives. In either case, these programs have similar objectives with the primary goal being to improve access to education for out-ofschool and excluded children and youth. Most common among these are programs involving the concept of accelerated learning.

The Valorisation de la Scholarisation de la Fille (VAS-Y Fille!) project - an initiative through the Girl's Education Challenge - sought to address this need with marginalized girls in the Democratic Republic of Congo (DRC). Indeed, one of the primary goals of this longitudinal initiative was to provide alternative learning opportunities to allow girls who were not enrolled in school to complete their primary school educations. To that end, Accelerated Learning Programs (ALPs) were funded in three provinces in the DRC targeting girls who had dropped out of school or who had never attended school and were too old to enroll in primary school. We examined the impact of the ALP component of this longitudinal initiative on student learning outcomes and traditional school enrollment. 


\section{Background on Accelerated Learning and Related Programs}

Accelerated learning is an educational concept that, in the early stages of its evolution, was based on Howard Gardner's (1983) theory of multiple intelligences, which suggests that people learn in various ways through emotional, social, physical, reflective, and cognitive learning systems. The concept changed and developed over decades to reflect new research and advances in psychology, neuroscience, and education as it became relevant. Between the mid-1990s and early 2000s, Smith (2003) simplified the original theory of multiple intelligences proposing different types of learning and combined his own work with previous research to produce an accelerated learning cycle that consists of four core elements and four general activities (Smith, 2003). In this cycle, as with the original theory, accelerated learning was not about increasing learning speed and allowing students to reach levels of achievement more quickly. Instead, the focus was on more effective and deeper learning (Charlick, 2004; Longden, 2013). Elements of this cycle were eventually incorporated in programs designed to help developing countries in their effort to reach the Millennium Development Goals, and it was in these contexts that condensed or compressed curriculums were first included (Menendez, Ramesh, Baxter, \& North, 2016). This modified model was adopted in various educational contexts and in many cases was used to create and implement structured alternatives or complementary educational programs.

These alternative/complementary education programs exist in numerous forms in different parts of the world and under a variety of diverse labels. For instance, in Ethiopia such programs are simply referred to as "Speed" schools, while programs in Ghana and Malawi are labeled as complementary basic education, or CBE, programs. The two most common terms used are Accelerated Education Programs (AEPs) and Accelerated Learning Programs (ALPs). The Accelerated Education Working Group (AEWG), a group commissioned by the United Nations to strengthen the quality of accelerated education programs, defines an AEP as follows:

Accelerated Education Programs (AEPs) are flexible, age-appropriate programs run in an accelerated time frame. The goal is to provide learners with a basic education that is certified and equivalent to the formal schooling system. (USAID ECCN, 2018)

Although some researchers in the field make a distinction between AEPs and ALPs, most use these terms interchangeably. From here on, for the sake of consistency with our own study, we refer to these programs as Accelerated Learning Programs, or ALPs.

The main purpose of an ALP is to encourage students to complete their learning at an accelerated rate. Although accelerated learning programs can be individualized or offered to small target groups such as advanced high school or college students who are aiming to reach a specific educational goal, many programs are targeted to a larger underserved population. In the case of adult education, this could mean allowing adults who were unable to get a high school credential to enroll in an abbreviated basic education program and gain their credential without having to attend years of school. In the case of primary or secondary schooling, it could mean moving students through a school system more quickly than traditional education programming can manage. It is important to note that ALPs are typically a form of complementary education, meaning that the program has the same end goal as a traditional or formal education system but attempts to reach that goal in less time. These programs are complimentary in the sense that they provide an alternative, shorter 
route while also matching their curriculum to the formal curriculum of the traditional school system. Thus, allowing students who take part in these programs to return to their formal schooling at some stage.

\section{ALPs in the Developing World}

As mentioned in a previous section of this paper, the accelerated learning cycle proposed by Smith (2003) was eventually adapted for use in emergency contexts, such as developing countries in crisis or conflict (Menendez et al., 2016). Initially, agencies and governments in developing countries simply used the original form of the accelerated learning cycle to improve their educational outcomes. However, the original model was not designed to be used in emergency contexts where challenges related to resources, teacher training, lack of materials, outdated curricula, and problematic governance abound (Buckland, 2006; Menendez et. al, 2016). In response to the ever-growing needs of these countries, the accelerated learning cycle was revised to reflect (1) condensed curriculum and content, (2) learner-centered, interactive pedagogy, and (3) extended instruction time. According to available records, the Liberia Ministry of Education first introduced this new model in 1999 (Manda, 2011). Use of the model spread quickly as it was adopted and modified in different countries and, although the programs all share certain features, they differ based on their purpose and consequent design.

Most ALPs in developing countries are implemented as a response to a lack of access to education; however, reasons for the limited access "are as varied as the programs themselves" (Menendez et al., 2016, p.5). When an ALP is implemented in response to a crisis or conflict, its purpose is more contextualized than the general purpose proposed in the theory of accelerated learning. As an illustrative example, consider the difference between the Afghanistan Primary Education Program (APEP) and the Brazil Accelerated Learning Program. The APEP was implemented in Afghanistan as a post-crisis measure "targeting an underserved population with a particular emphasis on females excluded from education" (Longden, 2013, p.13). This program covered two grades in one year, allowing students who were excluded from education due to conflict in the country to catch up with their peers. On the other hand, the Brazil ALP was implemented in 1996 to address the high percentage of overage students in the country's primary schools, which was a result of high rates of repetition "leading to $44.5 \%$ of primary school learners in 1995 being at least two age grades behind where they should be" (Longden, 2013, p.15). In this program students were supported through additional classes to fast-track more than one grade level in a school year. The initial target population for this program was fifth through eighth grade students, but in some areas, it was later expanded to include first through fourth grade. While the core objective in both these situations was to move students through a school system at a more accelerated pace than traditional education programming could manage, their specific purposes were aligned with their individual contexts and target populations. Consequently, these different individual contexts and purposes have an impact on the ALP design.

Depending on how an ALP operationalizes its curriculum and instruction time, the design and structure of the program varies and results in a certain degree of acceleration. Most programs operationalize their curriculum and instruction time based on specific contextual factors. APEP in Afghanistan, for instance, managed to reach their rate of acceleration (two grade levels in one academic year) by having students work through holiday periods and a longer academic year; thus, achieving more work in less time without expanding the instruction time of individual sessions. In the Menendez et al. (2016) program comparison report, evidence form several ALPs indicate that deviations of this nature are common in 
developing countries. These design decisions affect the rate of acceleration achieved as well as the overall period of the program.

The duration of an ALP is directly related to its purpose and design. Some programs are short term, as is typically the case when an ALP is implemented as a response to a crisis. For example, the previously mentioned APEP program in Afghanistan that was implemented in response to conflict was a short-term program that existed between 2003 and 2006 (Intili, Kissam, \& St. George, 2006). Because the purpose of the program was to allow primary school children affected by the conflict to catch up and return to their formal schooling, the design allowed for a compressed curriculum. Once the designated children completed the full primary cycle, the program was terminated as planned. Relatively few ALPs are ongoing initiatives. The Brazil ALP is one example of a continuing program and has been in existence since 1996. Although the program has been successfully reintegrating over-age students once they reach their appropriate grade level, the bottleneck created by the high rate of repetition in the lower grades has not been addressed; thus, the ALP continues to be necessary. Other long-term programs currently in existence include the Malawi Complementary Basic Education program and the Ghana Complementary Basic Education program (Jere, 2012; Longden, 2013). Preferably, an ALP would last as long as it takes to fulfill its purpose; however, pressures from government, donors, and unexpected situational issues (e.g., recurrent or new conflicts, natural disasters, etc.) all play a significant role in the ALP's duration. In addition, an ALP's duration could be extended to allow for multiple cycles in cases where the program evolved with the needs of its population. Ideally, any changes to the ALP's timeframe, design, or purpose should be made only after an empirical evaluation of the program that shows evidence supporting the need for such changes.

Because of the nature/context of these programs, strong evidence of both the internal and external validity of studies of ALPs can be difficult to establish. Still, reliable and unbiased evaluations of existing ALPs are a critical factor in the success of these programs as periodic empirical evaluations allow for the assessment of a program's impact as it relates to its purpose. Thus, adjustments can be made in cases where the ALP might otherwise fail to achieve its goal and evidence reported can inform other programs of the same nature. In the next section we review the reported impact and outcomes of several ALPs in developing countries, with a focus on student achievement and the effect of ALPs on traditional school enrollment.

\section{Access to Education}

Enrollment figures are typically used to measure access to education. Some evaluations report a single, overall enrollment figure for their programs, while others report figures across multiple time points throughout the life of the program. In many cases, local reports will compare ALP enrollment rates to traditional school enrollment rates. The same can be said for dropout and completion rates.

According to an EQUIP2 case study, ${ }^{2}$ the Bangladesh Rural Advancement Committee (BRAC) program showed a steady increase of enrollment rates from less than $0.1 \%$ of total primary school enrollment in 1985 to $8 \%$ in 2004 . The study also reported an attendance rate of $96 \%$ and a completion rate of roughly $90 \%$, which was compared to government school rates at $61 \%$ and $70 \%$, respectively (Chabbott \& Schuh Moore, 2006). Haque and Ahmed

2 The Education Quality Improvement Program 2 (EQUIP2) is a research initiative that provides support to USAID and governments across Africa, Asia, and Latin America to develop education policy and improve educational systems. 
(2011) looked at the impact of the BRAC program on the overall enrollment rate of primary schools in Bangladesh and found that the proportion of out-of-school children in the country decreased from 23.4\% to $13.6 \%$ between 1988 and 2008; however, since many other educational support programs were also put in place during this period, it is difficult to attribute the decrease to any one program (Ahmad \& Haque, 2011).

In Ghana, the school for life (SFL) program reported reaching roughly 110,000 learners between the program's inception in 1995 and 2012 (Longden, 2013). Northern Ghana, a region with an estimated $70 \%$ of the entire country's out-of-school population, had enrollment rates at $69 \%$ in 2000 (Hartwell, 2006; UIS, 2008). Attendance rates for SFL schools were at $90 \%$ (compared to $75 \%$ for public schools) and completion rates ranged from $65 \%$ to $95 \%$ depending on the region (Hartwell, 2006). In Malawi, the completion rates of their ALP program increased from $57 \%$ for the first cohort to $70 \%$ for the third cohort (Chiuye, \& Nampota, 2007; Moleni \& Nampota, 2006).

\section{Learning Outcomes}

Determining whether ALPs improve learning outcomes for their target population involves complex considerations. Factors to consider when trying to evaluate what students in ALPs are learning include the purpose of the program, the target population, and whether other options are available to these students (Menendez et al., 2016). Programs that report on their learning outcomes most often include average data on some type of internal assessment and, as in the case of enrollment rates, often compare these data to government schools.

In Bangladesh, the assessment for basic competencies (ABC) is a common metric used since 1992 to "rapidly assess basic literacy, numeracy, and life skills" in both government public schools and BRAC ALPs (Chabbott \& Schuh Moore, 2006, p. 5). In 1999, Chabbott and Schuh Moore (2006) reported that BRAC students scored an average of $69 \%$, which was compared to the $27 \%$ average obtained by students attending traditional government schools. A similar, but less profound, pattern was found for $5^{\text {th }}$ grade students who completed the secondary school scholarship exam. BRAC students passed at a rate of $13 \%$ compared to the $10 \%$ passing rate attained by the government school students.

In a quasi-experimental study on student performance in Ethiopia's Speed schools, researchers sampled 625 students from ALPs, government schools, and "improved" schools (government schools in which teachers were given additional training), respectively. Using propensity scoring to match students, the study lasted one school year, which equaled one academic year in the case of the government and "improved" schools and three academic years in the case of the Speed schools. Results indicate that students in Speed schools outperformed students from the other schools in literacy and math. Regression results show that Speed school students scored an average of 10.8 more points (out of 45) during the final exam on literacy compared with the average score of 22.4 attained by their government school counterparts. In terms of math, Speed school students scored an average of 9 points above their government school counterparts (Akyeampong et al., 2018). It should be noted at this point that, although the acceleration cycle for Ethiopia's Speed schools was designed to cover the equivalent of 3 traditional academic years, it is unclear whether this is the case in practice.

Both the PERP program in Liberia and the CREP program in Sierra Leone showed learning outcome progress on external measures. In Liberia, 71\% of the ALP students took the West African Examinations Council assessments and attained a 95\% average pass rate (Nkutu, Bang, \& Tooman, 2010). Likewise, over 90\% of the ALP students in Sierra Leone 
took the national primary exam and received passing rates similar to government school students (Baxter, \& Bethke, 2009).

\section{ALP IMPACT ON Traditional Schooling}

A potential tension exists between formal school systems and ALPs. On the one hand, there is a concern that ALPs will have a lower standard. On the other hand, when the ALP outperforms formal schools, there is the concern that the ALP will be in competition with the traditional school system. The latter should not be the case because, as stated earlier, an ALP serves a different target population and is designed to be complementary to the traditional school system. To evaluate whether an ALP has crossed the boundary between complimenting and undermining the formal school system, it is necessary to investigate the ALP's impact on traditional school enrollment. Unfortunately, few evaluations report on any measures related to this criterion.

In their comparative study on accelerated programs, Menendez et al. (2016) found that in some cases, school-aged children or youth enrolled in the accelerated program instead of attending traditional schools. Nicholson (2006) reported a similar finding and postulated that communities were naturally drawn by the advantage of free classes that also provided school materials. Theoretically, recruitment for accelerated programs should prioritize students with the greatest educational need with a focus on over-age learners who have been excluded or missed out on years of education. In Liberia, for instance, children and youth are tested against selection criteria before gaining entry to the program (Manda, 2011 ); however, many programs seem to operate on a simple first-come, first-served basis. There are various potential disadvantages associated with school-aged students attending the ALPs. As an example, consider the issues that might arise if primary-aged girls are attending class alongside over-aged peers: There is a heightened risk of these girls being subjected to higher levels of physical, sexual, or emotional abuse (UNICEF Annual Progress Report, 2007). Additionally, older students could be deterred from attending class with younger peers if they felt humiliated by their circumstances (Manda, 2011).

\section{Purpose}

The purpose of this study was to examine the impact of the Accelerated Learning Program component of the Valorisation de la Scholarisation de la Fille (VAS-Y Fille!) Intervention (VYF) on student learning outcomes and traditional school enrollment. Specifically, we address the following research questions:

1. Did girls advance through the ALP levels as expected?

2. To what extent did ALPs improve learning outcomes for out-of-school girls? Do these outcomes vary across province, initial ALP level, and/or previous schooling?

3. Is there evidence that the existence of ALPs has had an impact on traditional school enrollment?

\section{Setting: Democratic Republic of Congo (DRC)}

In DRC, a country located in the region of sub-Saharan Africa that is still recovering from war and conflict, the total population comprised over 77 million people in 2015, indicating a rapid increase from 66 million in 2012. The poverty rate is high and DRC's GDP is still among the lowest in the world, with $59 \%$ of the population surviving on less than $\$ 1.25$ per day (Gladwell \& Tanner, 2014). In DRC, the primary education attainment rate of approximately $15 \%$ among the poorest children did not change significantly between 2000 
and 2010 , yet increased from approximately $30 \%$ to $35 \%$ in average households, creating a gap of approximately $20 \%$ in educational attainment between children from the poorest and the average households (UN, 2015). Youth literacy rates, defined as a percentage of population over 15 years of age who can read and write, were at $79 \%$ for males and $53 \%$ for females in 2012 (UNESCO, 2013).

Unfortunately, conflict situations in DRC have left millions of people dead or displaced since 1996 (UN, 2015). According to 2012 UNICEF estimates, the war claimed three million lives in DRC, and renewed conflict in 2008 led to massive displacement of people, with the number of internally displaced individuals in eastern DRC being close to 1.7 million in 2011 (Aker, 2014). Ongoing conflict and subsequent economic crisis have devastating effects on the educational system; yet education is not categorized as immediate concern in an emergency, thus the lack of funding for education remains a huge problem (UN, 2015).

\section{The Intervention}

The Valorisation de la Scholarisation de la Fille (VAS-Y Fille!)- an initiative through the Girl's Education Challenge - targeted 100,768 marginalized girls in primary and lower secondary schools in Democratic Republic of Congo. The goal of this initiative was to increase families' financial capacity to support girls' primary schooling; set up teacher training, tutoring, and community reading programs to improve girls' reading and mathematics skills; increase community involvement to ensure girls' access to education; and increase civil society engagement in providing alternative learning opportunities to allow girls not enrolled in school to complete primary school. Here, we focus on the Accelerated Learning Program (ALP) intended to address the last goal. ALP classes target girls and boys who have dropped out of school or who have never gone to school and are now too old to enroll in primary school. Three years in an ALP allows these children to catch up and qualify to enter secondary school. These programs were implemented by local partners, ensuring that local actors developed the capacity to implement these kinds of activities. They were trained in using the national curriculum which was updated with the support of the VYF project. In some cases, children who never attended traditional schools were able to finish their primary education in ALPs and even earn primary completion certificates. The project provided financial support for ALP centers which enroll about 2,500 students each year. The reader should refer to Table 1 for a more detailed description of all of the project's components.

\section{Sample}

A longitudinal sampling approach was used to minimize unexplained error. The planned sample size for girls attending ALP centers, based on guidelines for multilevel analysis (Maas \& Hox, 2005) and logistical considerations, was at least 390 for each of four data collection waves. Sample sizes consistently exceeded the minimum requirement: 410 (Baseline), 412 (Annual Review), 522 (Midline), and 625 (Endline). Table 2 displays the number of girls sampled in each ALP level (1, 2, or 3) for each data collection wave. Using stratified random sampling to ensure a balanced number of girls at each level, baseline data were collected across 11 ALP centers in three provinces (Katanga, Orientale, and Equateur). ALP centers were identified by community partners. These partners worked with the project's implementers to extend services to and retention of out-of-school girls in these communities. Trained enumerators attempted to assess the same cohort of girls at subsequent data collection waves, but a replacement protocol had to be implemented due to attrition. 
Attrition was attributed to two causes (a) girls, due to a variety of reasons, were unable to continue taking ALP classes or (b) girls returned to traditional school. In any case, missing girls were replaced-by random selection-with new girls at each data collection wave.

Table 1.

Description of VTF Project Components

\section{Project Goal}

Increased parental

financial capacity to

support girls to succeed

in and complete

primary school.

Learning Outcomes

Community

Involvement \& Safe

Learning Environment

\section{Project Component}

Need-based scholarships and a voucher system were developed to help offset direct and indirect school costs so that parents could financially support their girls' education. Parents were also invited to participate in an innovative and highly sustainable Economic and Social Empowerment $(\mathrm{EA} \$ \mathrm{E})$ savings and loans program, where they participated in savings and loans groups, discussed socio-cultural norms related to girls' education, and were trained in small business skills in order to increase income generation. These components of the intervention were intended to boost attendance rates and encourage girls' school enrollment/re-enrollment in traditional primary school (when age appropriate).

The project worked with, and extended, the Ministry of Primary, Secondary, and Professional Education's (MEPSP) inservice teacher training modules on how to teach reading and math, how to ensure student wellbeing, and how to evaluate pupils' learning. Teachers received multiple layers of training that included an initial comprehensive workshop as well as ongoing weekly, monthly, and quarterly teacher learning circle (TLC) professional development sessions. Underperforming pupils also benefited from the VAS-Y Fille!'s community tutoring program, where secondary school pupils or graduates helped $3^{\text {rd }}$ to $6^{\text {th }}$ grade pupils learn basic skills in reading and math in afterschool tutoring sessions. Tutors also served as role models helping to develop pupils' confidence and create positive bonds with older peers. For students in younger grades, the project trained parents on home based pre-reading and reading activities. These interventions were designed to improve teaching and build essential skills for children in all primary school grades, with a specific focus on girls.

VAS-Y Fille! also brought reading into the home by engaging 7,500 parents of $1^{\text {st }}$ and $2^{\text {nd }}$ grade pupils in Save the Children's Literacy Boost community action approaches. Parents developed local 'Book Banks' and organized public reading events.

By actively leveraging the existing community commitment to education, the project aimed to build communities' capacities to implement local strategies to improve equitable access. Specifically, the project used mass-media and local "Back to 


\begin{tabular}{|c|c|}
\hline Project Goal & Project Component \\
\hline & $\begin{array}{l}\text { School Campaigns" as well as other community-led girls' } \\
\text { education awareness activities. School parent committees } \\
\text { (COPAs) were key project partners for the introduction of } \\
\text { gender-specific school improvements and community action } \\
\text { activities. These School Improvement Plans (SIPs) were } \\
\text { designed to build on awareness initiatives and included activities } \\
\text { to honor student and teacher performance throughout the year. } \\
\text { "Champions" of girls' education from civil society organisations } \\
\text { (CSOs), the private sector and the government were also trained } \\
\text { and supported to advocate for girls' education in provincial and } \\
\text { national policy forums. }\end{array}$ \\
\hline $\begin{array}{l}\text { Civil Society } \\
\text { Engagement and } \\
\text { Alternative Learning } \\
\text { Opportunities }\end{array}$ & $\begin{array}{l}\text { Education opportunities for over-aged girls and boys were } \\
\text { fostered through accelerated learning programs (ALP) that } \\
\text { condense the 6-year primary school curriculum into a 3-year } \\
\text { program. The project worked with local non-governmental } \\
\text { organizations (NGOs) and civil society organizations (CSOs) } \\
\text { who were, at that time of the projects onset, operating s ALPs in } \\
\text { project areas helping them/allowing them to expand access and } \\
\text { improve retention. }\end{array}$ \\
\hline
\end{tabular}

As a result, data collection waves after Baseline included a mix of persisting and newly recruited girls. The majority of girls only participated in one $(64 \%)$ or two $(30 \%)$ data collection waves. Fifty-four girls (4\%) were present from Baseline through Midline, and only $21(2 \%)$ participated in all data collection waves. At Baseline, the sample was evenly split in terms of the proportion of girls in level 1 (34\%), level 2 (33\%), and level 3 (33\%). At Annual, there were more girls in level $1(40 \%)$ than level $2(36 \%)$ and level $3(24 \%)$. At Midline, there were slightly more girls in level $2(47 \%)$ than level $1(45 \%)$, and much fewer girls in level 3 (8\%). Lastly, at Endline, the largest portion of the sample were still girls in level 2 (51\%), but there were substantially fewer girls in level $1(7 \%)$ and substantially more girls in level 3 (42\%). Girls' average age was 12.46 (SD = 2.11) at Baseline, $12.12(\mathrm{SD}=2.28)$ at Annual, $11.51(\mathrm{SD}=2.24)$ at Midline, and $12.89(\mathrm{SD}=2.04)$ at Endline. Across data collection waves, a high percentage of girls reported that Swahili was their preferred language (50\% to $66 \%$ ) while only a small percentage preferred French (5\% or less). Each year, slightly over half of the sample reported that they helped work in the fields or worked for their family outside of home $(51 \%$ to $58 \%)$. Among girls who had previously attended school, the percentage who indicated that their head of household or guardian was the person who made the decision that they should stop going to school ranged from $83 \%$ to $93 \%$ across data collection waves, and $4 \%$ to $10 \%$ of girls reported they made the decision themselves. When asked about who decided to enroll them in an ALP, $89 \%$ to $93 \%$ of girls across waves also reported that their head of household or guardian had made the decision, and $4 \%$ to $9 \%$ reported they made the decision to enroll themselves. At Endline, additional data were collected regarding the main reason girls stopped going to school. Ninety percent of girls who answered this question $(N$ $=489$ ) indicated the main reason was that their family did not have the money to pay for school fees; other reasons were the death of a caretaker $(2 \%)$, having to work or care for other 
children (1\%), being too old ( $1 \%)$, and being pregnant $(1 \%)$. The remaining $5 \%$ consist of less common reasons that were only reported by 1 to 3 girls each, including being displaced (0.6\%), sickness (0.4\%), and war (0.2\%).

Table 2.

Sample Size by Level Across Data Collection Waves

\begin{tabular}{lcccc}
\hline & Baseline & Annual & Midline & Endline \\
\hline Level 1 & 138 & 165 & 237 & 41 \\
Level 2 & 136 & 147 & 245 & 320 \\
Level 3 & 136 & 100 & 40 & 264 \\
Total & 410 & 412 & 522 & 625 \\
\hline
\end{tabular}

\section{Measures \& Analyses}

Early Grades Reading Assessment (EGRA). Children's literacy skills in French (the official language of the DRC) were assessed using the Early Grade Reading Assessment (EGRA; RTI International, 2009a). The EGRA was developed - in collaboration with scholars, practitioners, government official, and education development professionals- for several purposes including: (a) generating baseline data on early reading acquisition in particular grades and/or geographies; (b) identifying changes in reading levels over time, and (c) evaluating the outcomes or impact of programs designed to improve early grade reading. Although the assessment is designed to assess early grade reading skills, it is not grade specific, particularly given the contexts in which the assessment is administered (i.e. lowincome countries). Instead, the assessment is used to measure a wide array of literacy skills from the basic to more complex (in the case of this evaluation) over time. To that end, five popular subtests of the EGRA were used: Letter Recognition $(\alpha=.980)$, Invented Word Reading $(\alpha=.967)$, Oral Reading fluency $(\alpha=.987)$, Reading Comprehension $(\alpha=.787)$, and Oral Comprehension $(\alpha=.727)$. To reflect the relative importance of each subtest (as determined by key stakeholders), the EGRA assessment score was calculated to weigh the sections in the following manner: Letter recognition- 20\%, Invented word reading- 15\%, Words per minute- 45\%, Reading Comprehension- 10\%, and Oral Comprehension- 10\%. The EGRA takes about 15 minutes per child to administer, all of the subtests are orally administered, and some subtests are timed. The EGRA has been used in 31 different countries including DRC. Subtest instructions were translated into the relevant national languages (Kikongo, Lingala, Tshiluba, \& Swahili) in order to avoid bias from children not understanding instructions. To improve/maximize test security (i.e. to avoid the sharing and studying of test forms), new forms were developed for both the 2015 and 2016 EGRA administrations. Because different forms of a test may differ in difficulty, we used equating to insure that the 2015 and 2016 forms were comparable to the 2013/2014 form.

Early Grades Mathematics Assessment (EGMA). Children's math skills were tested using the Early Grade Mathematics Assessment (EGMA; RTI International, 2009b). Similarly to the EGRA, the EGMA is not a grade-specific assessment, but rather designed to assess specific math content and skills. Given the context of this project, five subtests were selected: Reading/Recognizing Numbers $(\alpha=.940)$, Comparing Quantities $(\alpha=.861)$, Number Sequences Missing Values $(\alpha=0.772)$, Addition $(\alpha=.911)$ and Subtraction $(\alpha$ $=.925)$. To ensure comparability of scores from different test forms, we equated each section of the test. As with the EGRA, the EGMA takes about 15 minutes per child to administer, 
all of the subtests are orally administered, and some are timed. The score calculations for both the EGRA and EGMA can be found in Table 3.

Table 3.

Weighting of EGRA and EGMA Percent-Correct Subtest Scores

\begin{tabular}{|c|c|c|c|}
\hline \multicolumn{2}{|l|}{ EGRA } & \multicolumn{2}{|l|}{$\underline{\text { EGMA }}$} \\
\hline Subtest & Weight & Subtest & Weight \\
\hline Letter recognition & 0.20 & $\begin{array}{l}\text { Reading/Recognizing } \\
\text { Numbers }\end{array}$ & 0.20 \\
\hline Invented Word Meaning & 0.15 & Comparing Quantities & 0.20 \\
\hline Words per Minute & 0.45 & $\begin{array}{l}\text { Number Sequences Missing } \\
\text { Values }\end{array}$ & 0.20 \\
\hline Reading Comprehension & 0.10 & Addition & 0.20 \\
\hline Oral Comprehension & 0.10 & Subtraction & 0.20 \\
\hline
\end{tabular}

ALP Girls' Survey. Girls' demographic characteristics were assessed through survey questions (administered orally) in which participating girls were asked about their home language, family structure, health and illness, means and time of transportation to school, absenteeism and tardiness, child labor, household composition, parents' literacy and education, and attitudes about school.

Household Survey. Community characteristics/demographics were collected through the oral administration of a Household Survey. The survey included similar questions to those included on the Girl's Survey. Enumerators questioned the primary caregiver or head of household about the household's primary language of communication, family structure including the number of children in the home, child labor practices, child and adult literacy, and attitudes about school including safety and financial concerns.

\section{Procedure: ALP Patterns}

Each ALP level represented two traditional in-school grades: Level 1 is equivalent to Grades 1 and 2 (typically for students with no prior schooling); Level 2 is equivalent to Grades 3 and 4; and Level 3 is equivalent to Grades 5 and 6. We would expect girls to move through one full level each year of the project. To examine the extent to which girls advanced through the levels of their ALP as expected, data from all girls who participated in two or more data collection waves were analyzed. First, the data were regrouped in relation to the number of data collection waves in which girls participated. Then, the frequency of girls following expected trajectories was computed for each group and common unexpected trajectories were noted. Depending on which data collection waves girls participated in, the "expected" pattern was slightly different because the Baseline and Annual waves happened at the beginning and end of the same academic year, respectively, while the Midline and Endline waves happened in separate years. Figure 1 shows all patterns that were considered expected. For example, for girls who were present from Baseline through Endline, the only expected pattern of progression through the ALP levels was 1-1-2-3. In other words, a girl enrolled in a Level 1 ALP class in September of 2013 would be expected to be in that same level class in June of 2014 (same academic year), but be present in the ALP Level 2 class in June of 2015 and in the Level 3 class in June of 2016. For a girl who was enrolled in Level 2 in June of 2014 (Annual Review), we would expect her to be enrolled in Level 3 in June 2015 (Midline); and then not present at all in June 2016 (as she would have 'graduated' to lower secondary 
school). An unexpected pattern might be a girl enrolled in a Level 1 ALP in September 2013 (Baseline) and June 2014 (Annual) and then again in June 2015 - as this would represent a lack of progression. Indeed, there were many possible trajectories for girls who participated in two or three data collection waves: 1-1, 2-2-, or 3-3 for girls who were only present at Baseline (September 2013) and Annual (June 2014) and 1-2 or 2-3 for girls who were only present at Annual and Midline, among other possibilities.

\begin{tabular}{|c|c|c|c|}
\hline $\begin{array}{l}\text { Baseline } \\
\text { Sept. } 2013\end{array}$ & $\begin{array}{c}\text { Annual } \\
\text { June } 2014\end{array}$ & $\begin{array}{c}\text { Midline } \\
\text { June } 2015\end{array}$ & $\begin{array}{c}\text { Endline } \\
\text { June } 2016\end{array}$ \\
\hline 1 & 1 & 2 & 3 \\
\hline$\rightarrow$ & $\rightarrow$ & 3 & - \\
\hline 3 & 3 & - & - \\
\hline- & - & 1 & 2 \\
\hline
\end{tabular}

Figure 1. Expected Patterns of Progression through ALP Levels

\section{Procedure: Achievement Outcomes}

In addition to examining basic descriptive information (mean scores over time), inferential methods were employed to determine if any causal relationships could be inferred, specifically hierarchical linear modeling (HLM). The use of HLM has two substantial benefits: (1) it allows for missing data at level one (time/test scores) so no students are removed from the overall analysis if they are missing one or more test scores; and (2) the nested nature of the data is accounted for in the parameter estimates. Moreover, the use of multi-level models allows for the inclusion, and more comprehensive interpretation, of multiple covariates. First, two unconditional models (no covariates) were fit to the data to examine the change in test scores over time:

Level 1

$$
\operatorname{EGRA}_{i j}=\beta_{0 j}+\beta_{l j} *\left(\mathcal{E} A R_{i j}\right)+r_{i j}
$$

Level 2

$$
\begin{aligned}
& \beta_{o j}=\gamma_{o o}+u_{o j} \\
& \beta_{l j}=\gamma_{\imath o}+u_{l j}
\end{aligned}
$$

where $E G R A_{i j}$ is the observed EGRA score of girl $j$ at time point $i ; \beta_{0 j}$ is the girl's estimated score at a given time point, which in this case was at Endline (based on how the YEAR variable was centered); $\beta_{1 j}$ indicates the estimated change in scores (slope) that happened from year to year, representing learning; and $r_{i j}$ is the person-specific residual, which indicates how far each person's pattern of observed scores is from the estimated trajectory for that person. In turn, at Level $2, \beta_{0 j}$ is defined as the average EGRA score at Endline across all ALP girls in the study, the intercept $\gamma_{00}$, plus the person-specific deviance/distance from that average, $u_{0 j}$. Finally, $\beta_{1 j}$ is defined as the average slope (representing the change in total scores for every year of the study), $\gamma_{10}$, plus the personspecific deviance from that slope. Note that the same model was fit to EGMA data by switching the outcome variable.

Next, to provide a more comprehensive evaluation of girls' learning, conditional models were fit to the EGRA and EGMA data. At level-1, the model was still defined as 
shown in Equation 1. The covariates considered at Level 2 (student) were (a) location/province of ALP Center, (b) previous school attendance, and (c) initial ALP level.

\section{Procedure: Impact on Enrollment}

To evaluate whether the existence of ALPs has had an impact on traditional school enrollment, we considered answers to survey questions regarding girls' perceptions of ALPs compared to tranditional schools as well as information regarding the age distribution of girls attending ALPs. It was hypothesized that a decrease in the average age of girls in ALP centers would indicate that families may be going directly to ALPs instead of considering them an option only after traditional school enrollment has become unfeasible.

\section{Results}

To examine whether girls progressed through the ALP levels as expected, we focused on girls who participated in two or more data collection waves. The possible "expected patterns" are shown in Figure 1. Girls enrolled in an ALP program at Baseline (Fall 2013) are expected to be at the same level at Annual Review (Spring 2014) as it represents one academic year. At the following two data collection periods, girls are expected to move up one ALP level and/or graduate from the program.

Table 4.

Patterns of Progression through ALP Levels

\begin{tabular}{ccccc}
\hline $\begin{array}{c}\text { Number } \\
\text { of waves }\end{array}$ & $N$ & $\begin{array}{c}\text { Expected } \\
\text { pattern }\end{array}$ & $\begin{array}{c}\text { Repeated a } \\
\text { level }\end{array}$ & $\begin{array}{c}\text { Skipped a } \\
\text { level or were } \\
\text { demoted }\end{array}$ \\
\hline 2 & 410 & $\begin{array}{c}340 \\
(82.93 \%)\end{array}$ & $\begin{array}{c}53 \\
(12.93 \%) \\
20\end{array}$ & $\begin{array}{c}17 \\
(4.14 \%)\end{array}$ \\
3 & 66 & $(69.70 \%)$ & $(30.30 \%)$ & - \\
\multirow{2}{*}{4} & 21 & $(47.62 \%)$ & $(52.38 \%)$ & - \\
\hline \multirow{2}{*}{ Total } & 497 & 396 & 84 & 11 \\
$(79.68 \%)$ & $(16.90 \%)$ & $(3.42 \%)$ \\
\hline
\end{tabular}

The actual patterns of progression can be found in Table 4. Although a total of 1364 girls were assessed across the four years of project implementation, 867 (63.56\%) were only present during one data collection wave. Among the girls who were assessed two or three times, the majority ( $82.93 \%$ and $69.70 \%$, respectively) progressed through the levels of the ALP program in expected ways, but a considerable proportion repeated at least one level $(12.93 \%$ and $30.30 \%)$. Furthermore, among the girls who were present during two waves, 9 skipped a level (e.g., level 1 at Midline and level 3 at Endline) while 8 were demoted to a lower level (e.g., level 2 at Annual and level 1 at Midline). Only 21 girls were present across all four data collection waves. Of those, approximately half followed an expected trajectory and the other half repeated a level at least once. Overall, $80 \%$ of girls who participated in two or more data collection waves followed an expected pattern. Taken together, these findings indicate that many girls only attended ALP centers for a short time, but those who stayed usually progressed through the levels in an expected pattern. 
To determine the impact of ALP attendance on learning outcomes, we examined both aggregate and subtest EGRA and EGMA scores across all four data collection waves. Figure 2 shows the changes in average aggregate test scores for ALP students in literacy and numeracy, respectively. In reading, the greatest overall gain was found between Midline (2015) and Endline (2016) administrations of the EGRA - a gain of approximately 16 percentage points. Gains, albeit smaller, were also recorded between Baseline (2013) and Annual (2014) as well as between Annual and Midline. With respect to EGRA subtest scores, shown in Figure 5, we see an increase in scores for all EGRA subtests between Baseline (September 2013) and Endline (June 2016). We found that the steepest increase, overall, was for the Listening Comprehension subtest. Interestingly, girls revealed a much slower rate of growth on the Reading Comprehension portion of the assessment. With respect to the numeracy achievement (Figure 2), we see a small dip (4 pts.) in average aggregate math scores between Baseline (2013) and Annual (2014). The loss was recovered, however, at the time of Midline data collection; and we see a substantial increase (12 pts.) between Midline and Endline. As with the EGRA, we found a steady increase in math performance within subtests (seen in Figure 6). Although in all cases we see a dip in scores between June 2014 and June 2015, girls' average scores increased across all subtests between Midline and Endline. Moreover, the growth rate for each subtest, unlike those of the EGRA, is comparable across all four data collection waves.

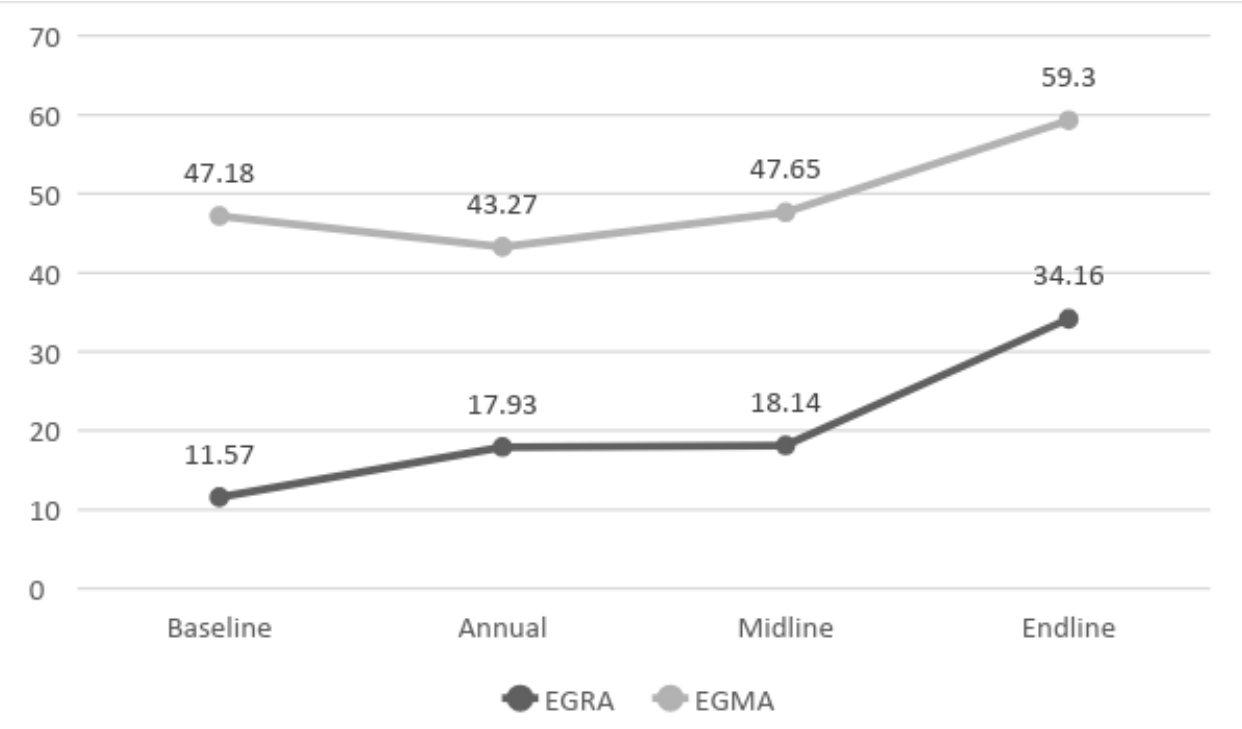

Figure 2. Aggregate EGMA and EGRA Scores for ALP Girls Across All Data Collection Waves

Given the rate of attrition (both anticipated due to girls returning to traditional school and unanticipated due to simple dropout), we also conducted a multi-level analysis of the data to account for missingness, as well as nested nature, of the data. Based on the unconditional model for the EGRA, which did not include any predictors other than "year/time," the estimated slope was $8.23(t=18.57, d f=1362, p<0.001)$, indicating that, on average, girls' EGRA scores improved by 8.23 points every year. An unconditional model was also fit to EGMA scores. The estimated slope was $6.61(t=15.11, d f=1363, p<.001)$, indicating that, on average, girls' EGMA scores improved by 6.61 points every year.

To further examine changes in girls' achievement in reading, the previous models were expanded to investigate potential differences in rates of learning (i.e., yearly changes in 
scores) across the three provinces from which girls were assessed (Katanga, Orientale, \& Équateur), across girls who began attending ALPs at different levels (1,2, or 3), as well as between girls with and without previous schooling. On average, the scores of girls in Katanga province increased by 16.24 points for each year of the study since Baseline $(t=19.43, d f=$ $1358, p<0.001)$. In Orientale province, the change was 13.26 points lower $(t=-14.06, d f=$ $1358, p<0.001)$, resulting in an estimated yearly change of 2.98 points. In Équateur province, the change in scores was 15.25 points lower than for Katanga province $(t=-17.23, d f=1358$, $p<0.001)$, resulting in an estimated yearly change of 0.99 . Neither previous schooling nor girls' initial ALP level had a significant effect on the rate of change.

In terms of factors that influenced the rate of learning in mathematics, there were once again significant differences across provinces. On average, the scores of girls in Katanga province increased by 10.72 points for each year of the study since Baseline $(t=12.57$, $d f=$ 1359, $p<0.001)$. In Orientale province, the change was 6.88 points lower $(t=-7.25, d f=$ $1359, p<0.001)$, resulting in an estimated yearly change of 3.84 points. In Équateur province, the change in scores was 4.13 points lower than the estimate for Katanga province $(t=-4.58$, $d f=1359, p<0.001)$, resulting in an estimated yearly change of 6.59. Additionally, it was estimated that the rate of learning (or yearly change in scores) was 1.58 points lower for girls who started the ALP program at level 2 and twice as many points lower (3.16) for girls who started the program at level $3(t=-3.11, d f=1359, p<0.05)$. Lastly, previous schooling did not have a significant effect on the rate of learning.

Finally, we sought to determine if the existence of ALP centers would have any impact on enrollment in traditional schools. Specifically, we wanted to address possible concerns that the presence of no-fee ALP opportunities would incent in-school girls to leave their traditional schools and enroll in ALPs. To that end, we examined (a) the age distribution of ALP enrolled girls across data collection waves and (b) previous enrollment patterns of ALP girls. Table 5 shows the average age as well as the age ranges of ALP enrolled girls across all four data collection waves. If the presence of an ALP center incentivized girls to leave their traditional schools for ALP schools, then one might expect the average age/age range of ALP girls to decrease. For example, an increase in the number of girls younger than 8 years old over the years would raise concerns. At Baseline, ages ranged from 7 to 18 and the average age was $12.46(S D=2.11)$. At Annual, the range was from 6 to 27 and the average age was $12.12(S D=2.28)$. At Midline, the range was from 7 to 34 and the average age was $11.51(S D=2.24)$. Finally, at Endline, the range was from 9 to 34 and the average age was $12.91(S D=2.02)$. Figure 3 and Figure 4 juxtapose the samples' ages at Baseline compared to Endline. Taken together, these pieces of information suggest no increase in the number of younger girls enrolling in ALP programs.

Table 5.

ALP Girls Demographic Characteristics

\begin{tabular}{lcc}
\hline & Average Age & Age Ranges \\
\cline { 2 - 3 } Baseline (Fall 2013) & $12.5(2.1)$ & $7-18$ \\
Annual Review (Spring 2014) & $12.1(2.3)$ & $6-27$ \\
Midline (Spring 2015) & $11.5(2.2)$ & $7-34$ \\
Endline (Spring 2016) & $12.9(2.0)$ & $9-34$ \\
\hline
\end{tabular}




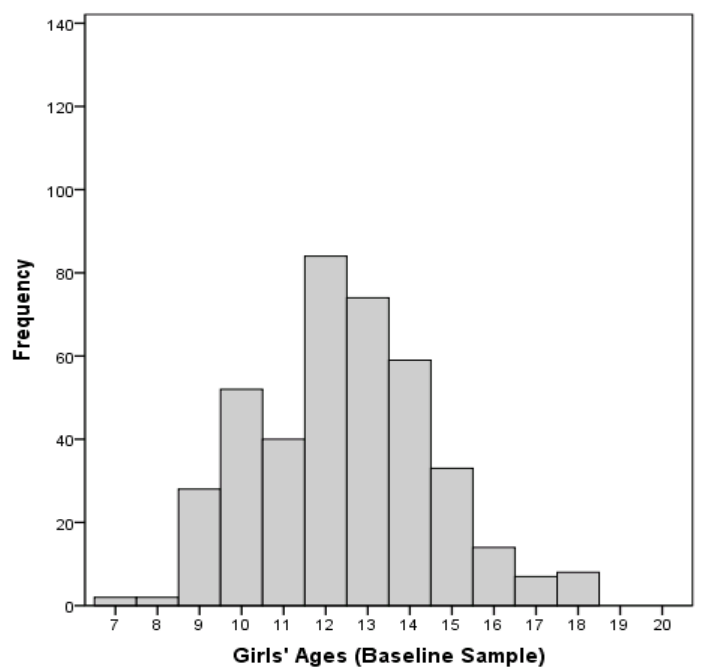

Figure 3. Distribution of ALP Girls' Ages at Baseline (September 2013)

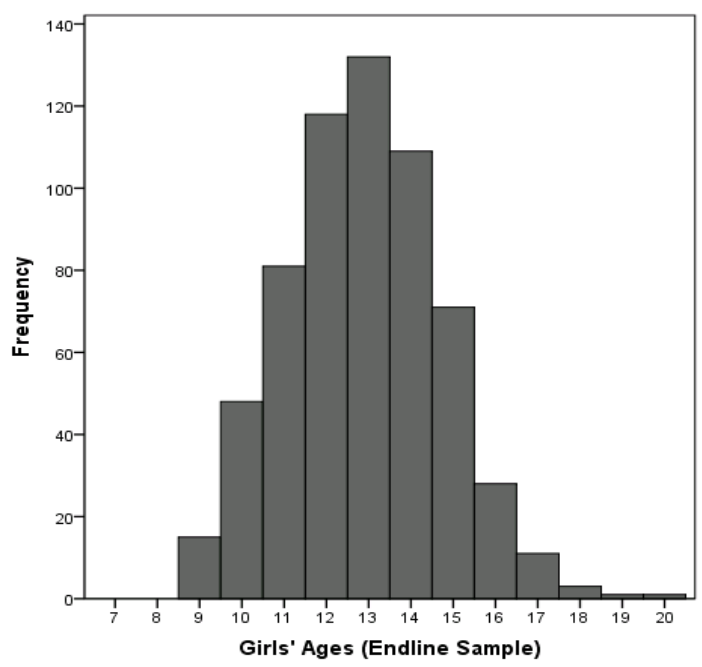

Figure 4. Distribution of ALP Girls' Ages at Endline (June 2016)

We also examined reported previous school attendance patterns of ALP girls (see Table 6). If the presence of a nearby no-fee ALP center incentivized students to leave traditional (sometimes fee-based) schools in favor of receiving an accelerated curriculum, one might expect more girls to report having recently left school. Although the percent of girls who previously attended school has remained stable (with the exception of a large decrease in 2015 , the percent of girls who were enrolled in school until the end of the previous year increased over the four data collection periods. In 2015 and 2016, girls were also asked additional questions about their ALP experience. In both years, the vast majority of girls reported that they preferred the ALP center to traditional school and nearly all (approximately 96\%) indicated that they learn more at the ALP center than at school. 


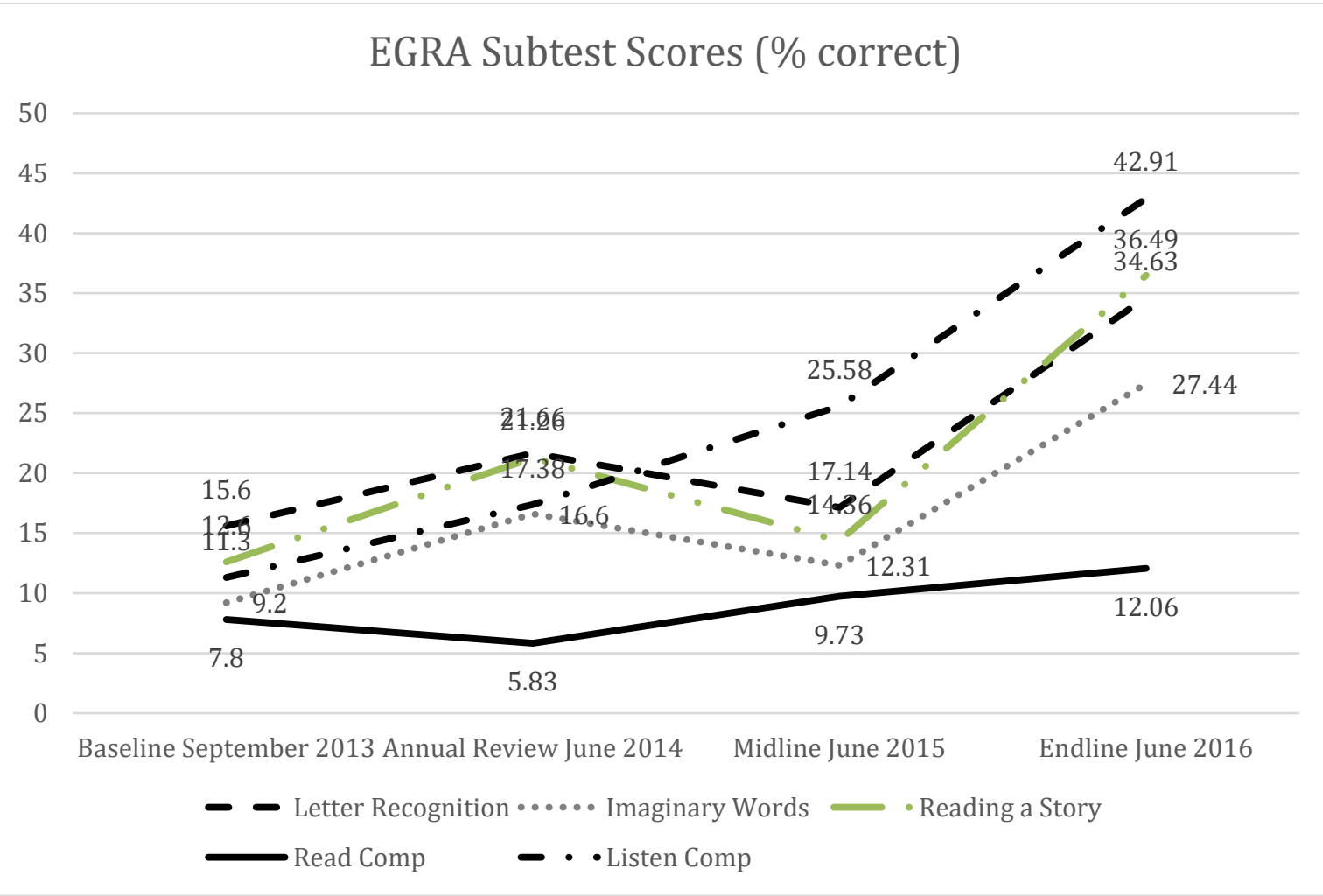

Figure 5. EGRA Subtest Scores

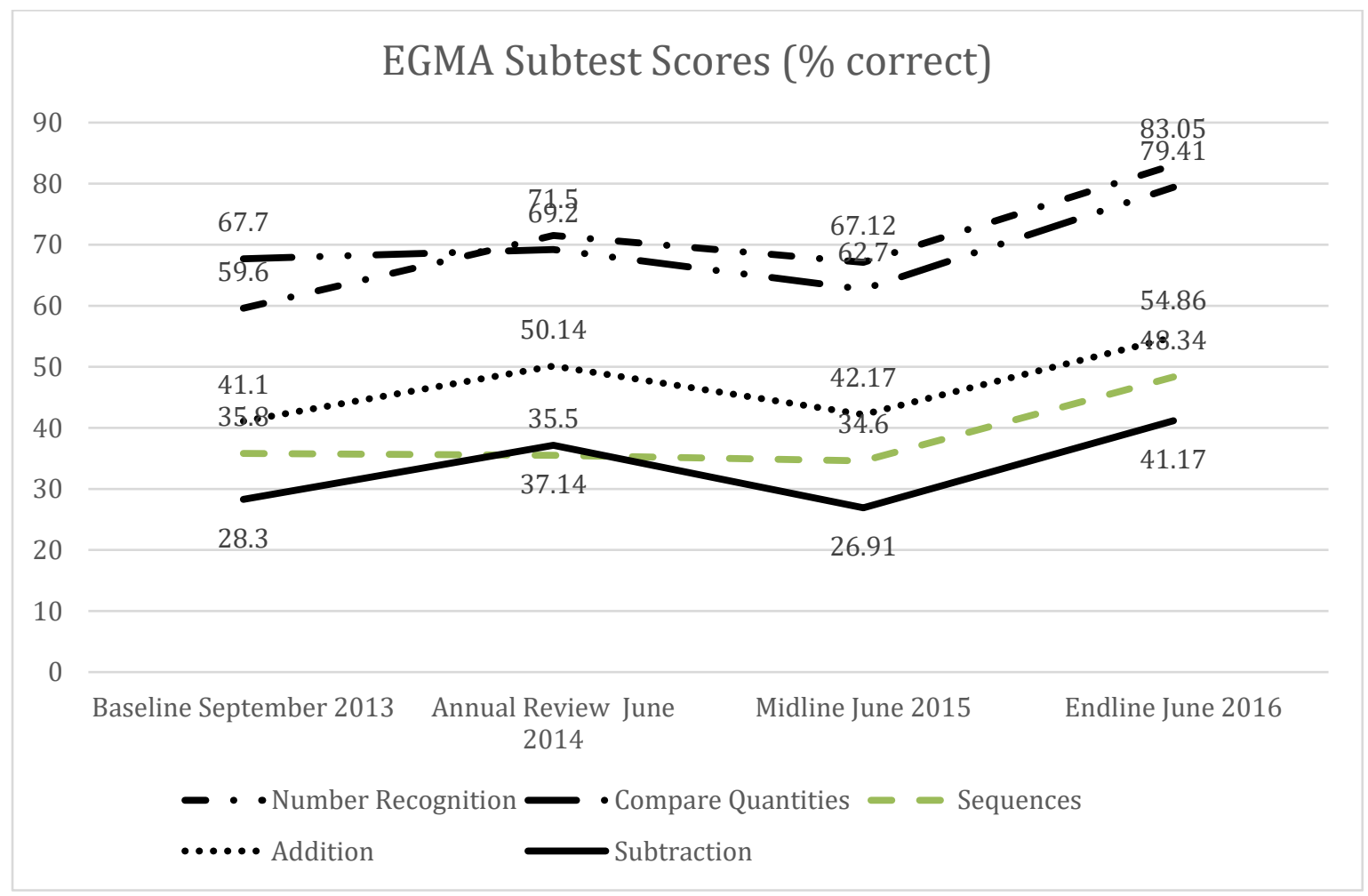

Figure 6. ALP EGMA Subtest Scores 
Table 6.

ALP Survey Responses

\begin{tabular}{lcccc}
\hline & $\begin{array}{c}\text { Baseline } \\
(2013)\end{array}$ & $\begin{array}{c}\text { Annual } \\
(2014)\end{array}$ & $\begin{array}{c}\text { Midline } \\
(2015)\end{array}$ & $\begin{array}{c}\text { Endline } \\
(2016)\end{array}$ \\
\cline { 2 - 5 } Girls who previously attended school not including & $76.1 \%$ & $76.9 \%$ & $60.5 \%$ & $78.4 \%$ \\
ALP & $(312)$ & $(317)$ & $(316)$ & $(490)$ \\
Girls who reported being enrolled in school until & $10.5 \%$ & $21.6 \%$ & $29.7 \%$ & $28.5 \%$ \\
the end of the last school year & $(43)$ & $(89)$ & $(155)$ & $(178)$ \\
Girls who would prefer to remain at the ALP center & - & - & $87.3 \%$ & $83.6 \%$ \\
than return to school & & & $(274)$ & $(407)$ \\
Girls who believe they learn more at the ALP center & - & - & $96.2 \%$ & $95.9 \%$ \\
than at school & & & $(303)$ & $(466)$ \\
\hline
\end{tabular}

\section{Discussion}

VAS-Y! Fille initiated Accelerated Learning Program (ALP) classes were available at no cost to out-of-school and unschooled young girls and boys ages 9-15 to help them complete a full cycle of primary school. To examine the extent to which girls progressed through the ALP levels as expected (research question 1), we focused on girls who participated in at least two data collection waves $(N=497)$. It was found that $80 \%$ of those girls did, in fact, advance as expected. However, it is important to note that $64 \%$ of the girls in the total sample $(N=1364)$ were only present for one wave. These results suggest that the majority of girls who persisted for more than one data collection made enough progress to be considered ready for the next level, but there was substantial attrition (in part due to students returning to traditional school, but also due to unexpected reasons). Still, given the context of the intervention the proportion of students who were able to move through the accelerated program is commendable.

Considering data from all girls who were present at least for one year, results indicate a steady increase in reading performance from Baseline through Midline, and a pronounced increase from Midline to Endline. Results regarding differences across provinces in the yearly rate of change (representing learning) revealed that the rate of change was highest in both literacy and numeracy Katanga and slowest in Orientale. Although previous schooling had no impact on girls' learning in literacy or numeracy, girls who began ALP in Level 2 classes (equivalent to $3^{\text {rd }} \& 4^{\text {th }}$ grade) improved at a greater rate in numeracy than girls who began at Level 1 or Level 3. To place our findings into context, we compared the aggregate EGMA and EGRA scores of ALP girls to the aggregate scores of in-school girls (those receiving additional intervention components detailed in Table 1 and those enrolled in control schools). The reader is reminded that the aggregate scores for ALP girls include girls at all three levels (which represent grades 1-6). These findings are presented in Figure 7. Although ALP girls' aggregate EGRA baseline scores were slightly lower than all in-school girls, their scores were near those of girls in intervention schools and higher than those in control schools at Endline. The same pattern is revealed when examining aggregate EGMA scores for in-school girls and ALP girls. These findings suggest that the ALP centers were on par, at least to some extent, with the growth outcomes of traditional schooling options. Although one might fear that ALP centers- given the very nature of the students they serve - may struggle to provide improved learning outcomes, this does not appear to be the case. These results are similar to those reported in previous studies of ALP programs in Bangladesh and Ethiopia.

The goal of the ALPs is to allow girls (who have been out of school) to complete their primary educations and hopefully move on to secondary school. An unintended consequence, 
of course, could be the cannibalization of traditional schools. The program's impact on traditional school enrollment, however, is less clear. The percent of girls in the ALP sample who previously attended school has remained stable (close to $77 \%$ for all waves except for Midline), but there was an increasing trend in the percent of girls who were enrolled in school until the end of the last school year. In terms of the distribution of girls' ages across the four data collection points, there was no increase in the number of girls younger than 8 years old over the years. However, it is important to note that the sampling strategy employed in this study was designed to facilitate analysis of learning by following specific cohorts to the extent possible.

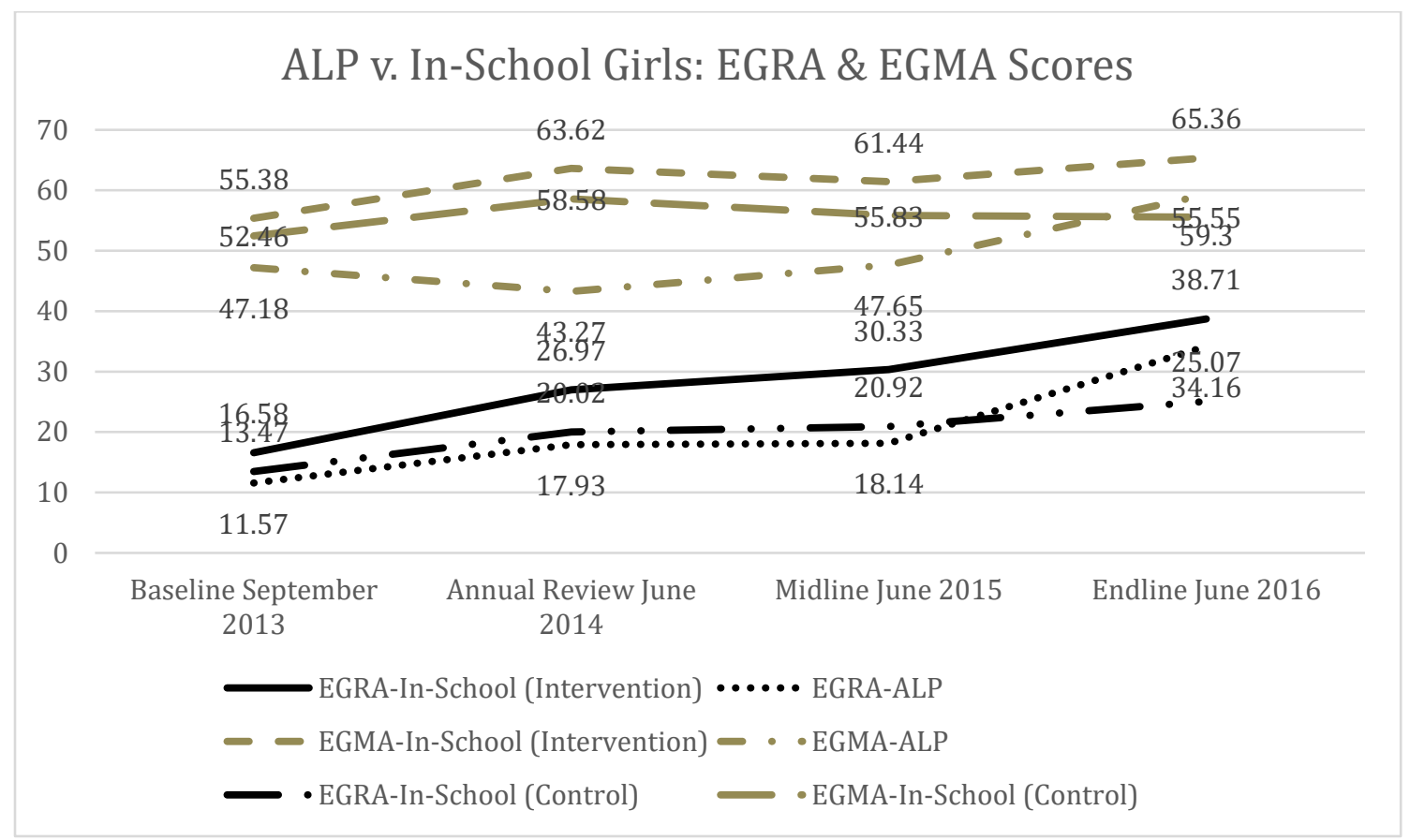

Figure 7. ALP v. In-School Girls: EGRA and EGMA Scores

It was not designed to keep track of changes in the ages of girls entering ALPs- the same applies to the dataset for in-school girls. Ideally, to answer the question of whether ALPs are affecting traditional school enrollment, it would be necessary to collect data from a representative sample of girls who are new to the ALP centers across levels every year. Given that $90 \%$ of girls at Endline who reported having previously attended school indicated that lack of money to pay for school fees was their primary reason for leaving school, it is likely that not having to pay for ALP classes is part of their appeal. Indeed, such reasoning is congruent with what was postulated by Nicholson (2006). Moreover, given girls' reported high esteem for the ALP centers, it is conceivable that girls sought instruction from ALP centers in lieu of the more traditional pathways. Indeed, these findings suggest the need for additional research into the culture and academic practices in ALP centers and how they differ from (and perhaps improve upon) those in traditional schools. Taken together, these findings highlight the importance of multi-faceted interventions that, in addition to providing more educational opportunities, improved teaching, and better schools, also seek to address financial and social barriers to girls' education. 


\section{References}

Ahmad, A., \& Haque, I. (2011). Economic and social analysis of primary education in Bangladesh: A study of BRAC interventions and mainstream schools. Research Monograph No. 48. Dhaka, Bangladesh: Research and Evaluation Division, BRAC.

Aker, J. C. (2014). Comparing cash and voucher transfers in a humanitarian context: Evidence from the Democratic Republic of Congo. Retrieved from http://sites.tufts.edu/jennyaker/files/2010/02/Cash_versus_Vouchers_1sept2014. pdf

Akyeampong, A., Delprato, M., Sabates, R., James, Z., Pryor, J., Westbrook, J., Humphreys, S., \& Tsegay, A.H. (2018). Speed School Programme in Ethiopia. Tracking the progress of Speed School students 2011-2017. Research Report. Centre for International Education, University of Sussex, Falmer, Brighton, UK.

Baxter, P. and Bethke, L. (2009). Alternative education: Filling the gap in emergency and postconflict situations. Paris, France: UNESCO.

Buckland, P. (2006). Post-conflict education: Time for a reality Check? Forced Migration Review, 7-8.

Chabbott, C., \& Schuh Moore, A.-M. (2006). Meeting EFA: Bangladesh Rural Advancement Committee (BRAC) primary schools (EQUIP2 Case Study). Washington, D.C.:

Education Quality Improvement Program 2 (EQUIP2), Academy for Educational Development (AED).

Charlick, J.A. (2004). Accelerating Learning for Children in Developing Countries: Joining Research and Practice. Washington, D.C.: Creative Associates International. Prepared for Basic Education and Policy Support (BEPS) Activity, USAID.

Chiuye, G.M. and Nampota, D.C. (2007). Complementary basic education in Malawi. Term three evaluation. University of Malawi, CERT.

Gardner, H. (1983) Frames of mind: The theory of multiple intelligences. New York City: Basic Books, Inc.

Gladwell, C. \& Tanner, L. (2014). Hear it from the children: Why education in emergencies is critical. London, UK: Save the Children.

Hartwell, A. (2006). Meeting EF A: Ghana School for Life (EQUIP2 Case Study). Washington, D.C.: Education Quality Improvement Program 2 (EQUIP2), Academy for Educational Development (AED).

Intili, J.A., Kissam, E. and St. Georg, E. (2006). Fostering education for female, out-ofschool youth in Afghanistan. Journal of Education for International Development 2:1.

Jere, C. M. (2012). Alternative approaches to education provision for out-of-school youth in Malawi: The case of complementary basic education. UNESCO. Retrieved from https://unesdoc.unesco.org/ark:/48223/pfoooo2 17881

Longden, K. (2013). Accelerated learning programmes: What can we learn from them about curriculum reform? Paper commissioned for the Education For All (EFA) Global Monitoring Report 2013/4. UNESCO. Retrieved from https://unesdoc.unesco.org/ark:/48223/pfoo00225950

Maas, C. J. M., \& Hox, J. J. (2005). Sufficient sample sizes for multilevel modeling. Methodology: European Journal of Research Methods for the Behavioral and Social Sciences, 1(3), 86-92.

Manda, S. (2011). Evaluation of the accelerated learning programme in Liberia. UNICEF. Retrieved from https://www.unicef.org/evaldatabase/index_70003.html

Menendez, A. S., Ramesh, A., Baxter, P., \& North, L. (2016). Accelerated Education Programs in Crisis and Conflict. Chicago: The Pearson Institute. 
Moleni, C.M. and Nampota, D.C. (2006). Complementary Basic Education in Malawi. Baseline Survey, Lilongwe, CERT.

Nicholson, S. (2006). Accelerated learning in post-conflict settings. Discussion Paper, Inter Agency Network for Education in Emergencies (INEE).

Nkutu, A., Bang, T. and Tooman, D. (April, 2010). Evaluation of NRC's Accelerated Learning Programme in Liberia. Norwegian Refugee Council.

RTI International. (2009a). Early Grade Reading Assessment toolkit. Prepared for the World Bank, Office of Human Development, under Contract No. 7141961. Research Triangle Park, NC: Author. Retrieved from https://s3.amazonaws.com/ineeassets/resources/EGRA_Toolkit_Mar09.pdf

RTI International. (2009b). Early Grade Mathematics Assessment (EGMA): A conceptual framework based on mathematics skills development in children. Prepared under the USAID Education Data for Decision Making (EdData II) project, Task Order No. EHC-E-02-04-00004-00. Retrieved from https://pdf.usaid.gov/pdf_docs/Pnads439.pdf

Smith, A (2003). Accelerated Learning: A User's Guide. Network Continuum Education

UIS. (September 2017). More Than One-Half of Children and Adolescents are not Learning Worldwide. UIS Fact Sheet No. 36. Montreal: UNESCO Institute for Statistics.

UIS. (February 2018). One in Five Children, Adolescents and Youth is Out of School. UIS Fact Sheet No. 48. Montreal: UNESCO Institute for Statistics.

UNESCO (2013). Adult and Youth Literacy: National, regional, and global trends, 19852015. UIS Information paper. UNESCO Institute for Statistics. Montreal, Canada.

UNICEF. (2007). UNICEF Annual Report 2007. UNICEF Liberia.

United Nations. (2015). Millennium Development Goals Report 2015. New York: Author.

United Nations. (2017). Sustainable Development Goal 4. Retrieved from https://sustainabledevelopment.un.org/sdg4

USAID ECCN. (2018). Accelerated Education Working Group: Principals in action. Retrieved from https://eccnetwork.net/events/aewg

World Conference on Education for All (1990). Meeting Basic Learning Needs: A Vision for the 1990s. Retrieved from https://unesdoc.unesco.org/ark:/48223/pfo000097552

\section{About the Authors}

Jennifer Randall is an Associate Professor in the Research, Educational Measurement, and Psychometrics program at the University of Massachusetts Amherst. Her research interests primarily reflect the measurement issues and concerns she encountered as a classroom teacher which include the grading practices/philosophies of teachers, particularly differential practices as they relate to students of color, first generation students, English learners, and students with disabilities. She is especially interested in the ways in which assessments (both large-scale \& classroom-based) take into consideration, and impact, historically marginalized populations in the U.S. and abroad. Currently, she is investigating the differential impact of licensure examinations on the certification rates of prospective teachers of color; and the resulting consequences on the learning experiences of students of color. At present, Dr. Randall serves as the Associate Dean of Academic Affairs and Director of Evaluation for the Center of Educational Assessment. She teaches courses in statistics, research methods, scale development, and measurement theory.

Francis O'Donnell is a Research Fellow at the Center for Educational Assessment at the University of Massachusetts Amherst. She earned her B.A. in psychology from Framingham State University and Ph.D. in Education from the University of Massachusetts 
Amherst. She has worked as an Assessment Analyst at a multi-campus community college, tutored students in need of academic support, and taught graduate-level courses in statistics and research methods. She has also completed internships at Educational Testing Service and the National Board of Medical Examiners. Her main areas of interest within education research are validity, fairness issues in assessment, and results reporting-especially how teachers, parents, and students make sense of achievement labels from tests.

Sandra Botha is a doctoral student in the Department of Educational Policy, Research, and Administration at the University of Massachusetts Amherst in the USA. Born and raised in Johannesburg, South Africa, she travelled to the USA and received a bachelor's degree in psychology from Mount Holyoke College in 2017. Her past research focused on examinee engagement, response processes, and validity issues in assessment for adult learners. She is particularly interested in the effect of student motivation on the validity of score-based inferences for low-stakes assessments that have a significant impact on educational policy. Her work has been presented at professional conferences such as the American Educational Research Association (AERA), National Council on Measurement in Education (NCME), and Northeastern Educational Research Association (NERA). Currently, she is investigating the effects of incorporating household, community, and cultural funds of knowledge on learning outcomes in elementary education. 